
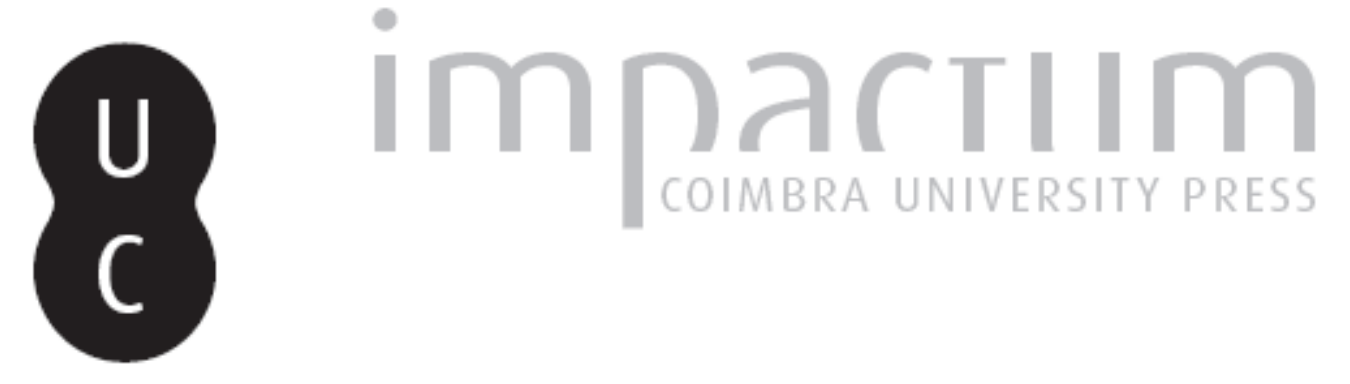

O consentimento informado de menores de idade na atividade pericial forense

\author{
Autor(es): $\quad$ Amorim, Ana
}

Publicado por: Imprensa da Universidade de Coimbra

URL persistente:

URI:http://hdl.handle.net/10316.2/33264

DOI:

DOI:http://dx.doi.org/10.14195/1647-8630_23_6

Accessed : $\quad$ 26-Apr-2023 11:07:22

A navegação consulta e descarregamento dos títulos inseridos nas Bibliotecas Digitais UC Digitalis, UC Pombalina e UC Impactum, pressupõem a aceitação plena e sem reservas dos Termos e Condições de Uso destas Bibliotecas Digitais, disponíveis em https://digitalis.uc.pt/pt-pt/termos.

Conforme exposto nos referidos Termos e Condições de Uso, o descarregamento de títulos de acesso restrito requer uma licença válida de autorização devendo o utilizador aceder ao(s) documento(s) a partir de um endereço de IP da instituição detentora da supramencionada licença.

Ao utilizador é apenas permitido o descarregamento para uso pessoal, pelo que o emprego do(s) título(s) descarregado(s) para outro fim, designadamente comercial, carece de autorização do respetivo autor ou editor da obra.

Na medida em que todas as obras da UC Digitalis se encontram protegidas pelo Código do Direito de Autor e Direitos Conexos e demais legislação aplicável, toda a cópia, parcial ou total, deste documento, nos casos em que é legalmente admitida, deverá conter ou fazer-se acompanhar por este aviso.

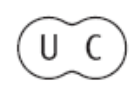


REVISTA PORTUGUESA

$\stackrel{\infty}{\cdots}$

$\stackrel{2}{i}$

$\dot{\bar{x}}$

$\bar{x}_{\bar{x}}$

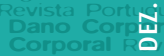

Oeno dorporal Revista Portuguesta do Dano Corporal Revista Portuguens do Dano Corporal

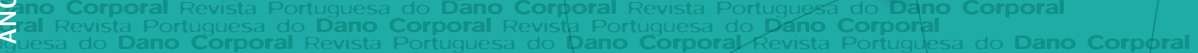

Rvista Portuguesa do Dano Corporal Revista Portuguesa do Dano Corporal Revista Portuguesa do pang Coporal

NPortuguesa do Dano Corporal Revista Portuguesd do Dano Corporal

Silo

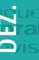

\section{APADAC}

ASSOCIAÇÃO PORTUGUESA

DE AVALIAÇÃO

DO DANO CORPORAL

INSTITUTO NACIONAL

DE MEDICINA LEGAL, I.P.

DELEGAÇÃO DO CENTRO 


\title{
O consentimento informado de menores de idade na atividade pericial forense
}

\author{
Ana Amorim ${ }^{1}$
}

\section{O CONSENTIMENTO INFORMADO}

A necessidade de obtenção prévia do consentimento informado ${ }^{2}$ para a prática de um ato médico assume, atualmente, um lugar de destaque no que concerne à relação estabelecida entre médico e paciente. Porém, esta é uma realidade muito distinta da que se verificava até há poucos anos, quando a prática médica era pautada por alguma desumanização dos cuidados de saúde 3 . Vivia-se então a época do paternalismo clínico herdado de Hipócrates ${ }^{4}$, na qual o médico, enquanto sujeito possuidor de mais conhecimentos e competências

1 Estudante do Doutoramento Interdisciplinar em Ciências Forenses da Universidade do Porto, sob orientação da Prof. Doutora Luísa Neto, Professora Associada da Faculdade de Direito da Universidade do Porto e coorientação da Mestre Rute Teixeira Pedro, Assistente da Faculdade de Direito da Universidade do Porto.

2 O consentimento informado "significa o comportamento mediante o qual se concede a alguém algo, como seja, uma determinada atuação, no caso do consentimento para o ato médico, uma atuação do agente médico na esfera físico-psíquica do paciente com o sentido de proporcionar saúde em benefício do próprio, ou benefício alheio ou em benefício geral" -, de acordo com a lição de Orlando de Carvalho na preleção proferida a 13.01.1996 apud RODRIGUES, João Vaz - O Consentimento Informado para o Acto Médico no Ordenamento Jurídico Português (Elementos para o Estudo da Manifestação da Vontade do Paciente), Coleção do Centro de Direito Biomédico n ${ }^{\circ} 3$, Coimbra: Coimbra Editora, 2001, p. 24, nota de rodapé n. ${ }^{\circ} 7$.

3 De referir que esta desumanização do paciente tinha como fundamento o próprio Juramento de Hipócrates, uma vez que este, ainda que implicitamente, transmitia a ideia de que o "paciente não tem cara", como refere Rafael Vale REIS, O Consentimento na Relação Médico Paciente, texto do Centro de Direito Biomédico da Faculdade de Direito da Universidade de Coimbra, p. $4<$ https://woc.uc.pt/feuc/getFile.do?tipo=2\&id=10370 >.

4 Neste sentido, veja-se André Gonçalo Dias PEREIRA, Responsabilidade Médica e Consentimento Informado. Ónus da Prova e Nexo de Causalidade - conferência apresentada no Centro de Estudos Jurídicos e Judiciários da Região Administrativa de Macau, República Popular da China, a 18 de Julho de 2008, p. 2 < http://www.estig.ipbeja.pt/ ac_direito/ResponsabilidadeM.pdf $>$. 
ao nível médico, decidia pelo doente de acordo com o que acreditasse ser a melhor opção perante o caso concreto ${ }^{5}$. Contudo, recentemente, temos assistido a uma mudança de paradigma no que respeita à atitude do médico perante o doente; ao contrário do que se verificava no passado, hoje o médico vê-se obrigado a esclarecer o doente quanto ao diagnóstico, alcance, consequências e eventuais riscos do ato médico a realizar ${ }^{6}$ e a obter o seu prévio consentimento informado, baseado numa vontade séria, livre e esclarecida ${ }^{7,8}$.

Embora exista, ainda hoje, uma lacuna no ordenamento jurídico português quanto ao conceito de ato médico ${ }^{9}$, as perícias médico-legais devem ser consideradas verdadeiros atos médicos ${ }^{10}$ pelo que, durante a sua realização, o médico deve adotar o comportamento que se mostre adequado de acordo com as leges artis ${ }^{11}$; na sequência do que resulta dito, também para a realização de perícias forenses, no âmbito dos serviços da clínica médico-legal, o profissional deve fornecer todas as informações que se revelem

5 O paciente assumia, deste modo, uma postura passiva no que dizia respeito às decisões sobre a sua saúde e o seu corpo.

6 Veja-se o artigo $157^{\circ}$ do Código Penal, doravante referido apenas como CP.

7 Com esta obrigatoriedade, o legislador procurou respeitar e salvaguardar o direito de cada paciente à sua integridade física e moral, bem como o seu direito à autonomia e autodeterminação (neste sentido veja-se Guilherme de OLIVEIRA, Estrutura Jurídica do Acto Médico, Consentimento Informado e Responsabilidade Médica apud OLIVEIRA, Guilherme - Temas de Direito da Medicina, $2^{\mathrm{a}}$ ed. aumentada, Coleção do Centro de Direito Biomédico $\mathrm{n}^{\circ} 1$, Coimbra: Coimbra Editora, 2005, pp. 59-72, p. 63). Assim, o doente enquanto sujeito capaz de decidir o que é melhor para si e para o seu corpo, de acordo com a sua vontade, crenças e modo de vida, adota um papel ativo na relação estabelecida entre médico e paciente.

8 Veja-se Paulo Pinto de ALBUQUERQUE Comentário do Código Penal à luz da Constituição da República e da Convenção Europeia dos Direitos do Homem, $2^{\mathrm{a}}$ ed. atualizada, Lisboa: Universidade Católica Editora, 2010, comentário ao artigo 38 , p. 198.

9 A 24 de Setembro de 1999, o então Presidente da República, Dr. Jorge Sampaio, vetou o decreto-lei que propunha a definição de ato médico, como lembra Luísa NETO, em A infecção por VIH resultante de transfusão de sangue contaminado no contexto da responsabilidade civil extracontratual do Estado in Estudos em Homenagem ao Prof. Doutor Sérvulo Correia, (Coordenação Prof. Doutor Jorge Miranda), Coimbra: Coimbra Editora, 2011, Volume II, pp. 657-694, p. 660.

10 Teresa MAGALHÃES, Introdução à Clínica Forense, 30 de Novembro de 2010, p.2

11 No que respeita aos exames médico-legais, André Gonçalo Dias PEREIRA - em O Consentimento (Informado) na Actividade Pericial Forense in Revista Portuguesa do Dano Corporal. Ano XIV, n. ${ }^{\circ}$ 15. Coimbra: Edição APADAC, 2005, pp. 9-43, p. 23 - refere que estes afetam o bem jurídico integridade física, uma vez que a realização de uma perícia forense não tem como objetivo "prevenir, diagnosticar, debelar ou minorar doença, sofrimento, lesão ou fadiga corporal, ou perturbação mental", tal como previsto no n. ${ }^{\circ} 1$ do artigo $150^{\circ}$ do CP. Porém, ainda que as perícias médico-legais não visem, diretamente, nenhuma das situações previstas no artigo supramencionado, a sua realização sem a prévia autorização do avaliado ou avaliada, pode levar a que o médico incorra em responsabilidade penal por ofensa à integridade física da pessoa alvo da perícia. 
necessárias perante o caso concreto e, posteriormente, proceder à recolha do consentimento informado do examinando ou examinanda ${ }^{12}$ (ou do seu representante legal, caso a pessoa não possua capacidade de decidir $)^{13}$.

\subsection{Em especial, da capacidade para consentir}

Atendendo à letra da lei do atual Código Civil português ${ }^{14}$, é menor de idade quem não tiver ainda completado dezoito anos de idade ${ }^{15,16}$; assim, até atingir essa idade-limite, o jovem carece de capacidade para o exercício de direitos ${ }^{17,18}$.

Já no que diz respeito, especificamente, à capacidade para consentir, o $\mathrm{n}^{\circ} 3$ do artigo $38^{\circ}$ do $\mathrm{CP}$ estabelece dois requisitos cumulativos, para que o consentimento seja eficaz perante a lei: tem de ser prestado por quem tenha mais de 16 anos $^{19}$ e possua o "discernimento necessário para avaliar o seu sentido

12 Maria Teresa Criado del RIO, Visión médico legal del secreto profissional médico y del consentimento informado: su aplicación en la función médico pericial in Revista Portuguesa do Dano Corporal. Ano X, n. ${ }^{\circ}$ 11. Coimbra: Edição APADAC, 2001, pp. 77-127, p. 105 e ss.

13 Embora a lei não exija nenhum formalismo específico para a manifestação do consentimento informado, acreditamos que a situação ideal se baseia num consentimento escrito, sendo que o documento original deverá ser anexado ao processo e um duplicado entregue ao examinando ou examinanda ou ao seu representante legal.

14 Doravante referido apenas como CC.

15 Aplica-se aqui o artigo $122^{\circ}$ do CC.

16 Ainda que o artigo $122^{\circ}$ do CC estabeleça a maioridade civil a partir dos 18 anos, nada é referido quanto ao conceito específico de criança, pelo que, neste ponto, teremos de remeter a nossa análise para a Convenção sobre os Direitos da Criança, adotada pela Assembleia Geral das Nações Unidas a 20 de Novembro de 1989 e, posteriormente, ratificada por Portugal a 21 de Setembro de 1990, cujo artigo n. $^{\circ} 1$ estabelece que "criança é todo o ser humano menor de 18 anos, salvo se, nos termos da lei que the for aplicável, atingir a maioridade mais cedo."

17 Este regime resulta do artigo $123^{\circ}$ do CC.

18 Neste ponto, importa salientar que a lei civil, no artigo $124^{\circ}$, permite o suprimento da incapacidade dos menores de idade através do poder paternal, bem como do recurso ao instituto da tutela.

19 De ressalvar que, em 2007, com a Lei 59/2007, de 04 de Setembro, que estabelece a $23^{\mathrm{a}}$ alteração ao $\mathrm{CP}$, o legislador decidiu aumentar a idade-referência do consentimento do $\mathrm{CP}$, de 14 anos para 16 anos procurando, porventura, com essa decisão, uma maior proteção do menor de idade numa fase da vida tão vulnerável, bem como a uniformização da lei, no ordenamento jurídico português. Porém, este aumento da idade-limite parece contrariar a tendência ao nível do direito comparado, que pretende conferir uma maior autonomia ao menor de idade (neste sentido veja-se André Gonçalo Dias PEREIRA, O Consentimento (Informado)..., ob. cit. p. 18). A título de exemplo, em Novembro de 2012, são já vários os estados norte-americanos que estabelecem os 12 anos como a idade mínima para que um menor possa consentir num ato médico específico, como decorre do relatório do GUTTMACHER INSTITUTE - An Overview of Minor's Consent Law, State Policies in Brief - 01 de Novembro de $2012<$ http://www.guttmacher.org/statecenter/spibs/spib_OMCL.pdf>. 
e alcance no momento em que o presta". Embora o artigo supramencionado se refira ao consentimento em geral, ele deverá também ser aplicado quando estejamos perante a prática de um ato médico, sendo que, nesta situação, o discernimento fundamenta-se na capacidade do jovem em compreender os esclarecimentos do médico, o tratamento a realizar, a sua duração e recuperação, assim como eventuais consequências e riscos. Deste modo, ao exigir a verificação cumulativa destes dois requisitos, a lei penal não permite que um jovem de 15 anos preste um consentimento informado válido para a realização de um ato médico, mesmo que possua o discernimento necessário para compreender o alcance da sua decisão.

\section{A ATIVIDADE PERICIAL MÉDICO-LEGAL}

\subsection{0 dever de esclarecimento para o ato pericial}

Tratando-se de um ato médico - ao qual naturalmente se aplicam as regras deontológicas da atividade médica, nomeadamente, o respeito pela dignidade, autonomia e autodeterminação da pessoa -, também a atividade pericial forense deve ser precedida dos esclarecimentos que o profissional entenda serem necessários perante o caso concreto ${ }^{20}$. Com base neste dever de esclarecimento, o médico deve proceder a uma explicação adequada, clara e suficiente dos procedimentos que serão realizados no decorrer da perícia médico-legal ${ }^{21}$, tentando deste modo estabelecer uma relação de confiança ${ }^{22}$ entre si e o examinando ou examinanda; importa ressalvar que essa relação que, eventualmente, se possa estabelecer entre os intervenientes, surge como um elemento essencial à realização da perícia pois, ao criar um ambiente de confiança, o profissional permite que o avaliado ou avaliada se sinta confortável e o mais à vontade possível, perante uma situação de maior fragilidade. É precisamente através do dever de esclarecimento que o médico possibilita que a pessoa alvo da perícia tome uma decisão consciente e fundamentada tendo por base a sua vontade, bem como as informações previamente fornecidas.

\footnotetext{
20 Neste sentido, veja-se o artigo $44^{\circ}$ do Código Deontológico da Ordem dos Médicos (CDOM).

21 Esta formulação é de João Vaz RODRIGUES, O Consentimento Informado .... ob. cit., pp. 222 e ss.

22 O médico deve ainda mostrar-se disponível para esclarecer todas as questões colocadas pelo sujeito alvo da perícia.
} 


\subsection{Quem recebe a informação quando a perícia é realizada a um menor de idade?}

Todas estas informações devem ser prestadas diretamente ao examinando ou examinanda, visto ser ele ou ela o titular do direito à informação ${ }^{23}$. Contudo, dúvidas podem surgir quando a vítima é um menor de idade; perante situações concretas que envolvam menores de idade, deve o médico prestar todas as informações necessárias a este ou aos seus representantes legais que, eventualmente, o acompanharam aos serviços médico-legais? Embora a letra da lei estabeleça os 16 anos como idade-limite para prestar o consentimento, parece-nos que, mesmo nas situações em que o jovem tenha uma idade inferior a 16 anos, mas possua o discernimento necessário, atendendo ao tipo de bens jurídicos que possam estar em causa, ele deve ser ouvido ${ }^{24} \mathrm{e}$ envolvido no processo de esclarecimento ${ }^{25}$, existindo aqui uma preocupação pelo respeito da autonomia do menor. Assim, o médico deve esclarecer tanto os representantes legais, que podem e devem auxiliar o menor de idade no processamento de toda a informação, como o próprio jovem enquanto vítima e objeto da intervenção médico-legal ${ }^{26}$; mesmo nos casos em que a perícia médico-legal tenha sido ordenada pelo tribunal, o médico deve obter o consentimento informado do representante legal da criança ou do próprio examinando ou examinanda, desde que preenchidos os requisitos do já referido $\mathrm{n}^{\circ} 3$ do artigo $38^{\circ}$ do $\mathrm{CP}$, explicando ainda a finalidade do exame a realizar, assim como todas as técnicas que serão utilizadas no decorrer da perícia $^{27}$. Porém, todas as informações prestadas ao menor de idade devem

23 De acordo com o n. ${ }^{\circ} 1$ do artigo $3^{\circ}$ da Lei n. ${ }^{\circ}$ 12/2005, de 26 de Janeiro, que estabelece o regime jurídico referente à informação genética pessoal e à informação de saúde, "a informação de saúde, incluindo os dados clínicos registados, resultados de análises e outros exames subsidiários, intervenções e diagnósticos, é propriedade da pessoa". Esta evidência é ainda ressaltada por André Gonçalo Dias PEREIRA, O Consentimento (Informado) ..., ob. cit., p. 14.

24 Assim defende Helena Gomes MELO [et al.] - Poder Paternal e Responsabilidades Parentais - Lisboa: Quid Juris Sociedade Editora, 2009, p. 33.

25 Principalmente no que respeita a perícias que têm por base um crime de natureza sexual praticado contra o menor de idade, estas vão intervir na esfera mais íntima deste, razão pela qual defendemos que o examinando ou examinanda também deve ter acesso à informação adequada. Contudo, as informações reveladas não devem ser suscetíveis de provocar ainda mais ansiedade do que aquela que a criança já vivencia, apenas pelo facto de estar perante uma situação eventualmente nova e desconhecida.

26 Teresa MAGALHÃES, A Vítima como objecto da intervenção médico-legal in Acta Médica Portuguesa, II série, volume 18, n. ${ }^{\circ}$ 6, Novembro/Dezembro, 2005, pp. 453-458, p. 453.

27 Veja-se Teresa MAGALHÃES A Intervenção médico-legal em casos de maus tratos em crianças e jovens, in Cuidar da Justiça de Crianças e Jovens - A Função dos Juízes Sociais, Actas do Encontro (coordenação Maria Clara Sottomayor); Coimbra: Editora Almedina, Outubro de 2003, pp. 175-188, p. 178. 
ser adequadas à sua idade, bem como à sua capacidade de compreensão, pelo que o médico terá de fazer uma avaliação casuística, uma vez que cada criança é única e o seu discernimento depende de vários fatores específicos daquele jovem em concreto.

\subsection{O direito a recusar}

\section{a) A recusa na realização de uma perícia médico-legal}

Se por um lado o examinando ou examinanda tem a capacidade de consentir no que pode ou não ser feito ao seu corpo, enquanto sujeito de direitos, ele ou ela possui ainda autonomia para recusar a realização de um determinado ato médico, como é o caso específico das perícias médico-legais; esta possibilidade de recusa baseia-se no direito constitucionalmente consagrado do livre desenvolvimento da personalidade ${ }^{28}$.

Deve ainda salientar-se que é através da perícia médico-legal, realizada nos serviços de clínica forense, que se procede à avaliação das lesões físicas ou psíquicas de uma pessoa, permitindo conhecer os danos sofridos, suscetíveis de fundamentar a aplicação de uma sanção penal ou de uma indemnização ${ }^{29}$; após a realização desta perícia, o profissional elabora um relatório final, do qual constam todas as informações essenciais decorrentes da avaliação concretamente efetuada e que, posteriormente, será remetido para Tribunal, auxiliando, porventura, na descoberta da verdade material. Enquanto meio de prova admitido por lei ${ }^{30}$, o relatório pericial é um instrumento adequado a auxiliar o Ministério Público na decisão de deduzir acusação contra uma determinada pessoa; perante uma recusa do examinando ou examinanda, o relatório elaborado pelo profissional, não possuirá os elementos de que o Ministério Público necessita, em muitos casos, para sustentar a acusação, o que pode, eventualmente, conduzir ao arquivamento do processo. Assim, quando confrontado com uma recusa para a realização da perícia, o médico deve alertar a pessoa para as consequências jurídicas da sua decisão, nomeadamente, o risco de arquivamento do processo ${ }^{31}$, bem como outras

28 Previsto, entre nós, no ${ }^{\circ} 1$ do artigo $26^{\circ}$ da Constituição da República Portuguesa, doravante referida como CRP.

29 É esta a proposta de Teresa MAGALHÃES, Introdução à Clínica..., ob. cit., p. 1.

30 Vejam-se os artigos $151^{\circ}$ e ss. do Código de Processo Penal (doravante referido apenas como CPP) e artigo $568^{\circ}$ e ss. do Código de Processo Civil.

31 Embora estejamos aqui perante questões de teor puramente jurídico, entendemos que deve ser o médico, num primeiro momento, a facultar estas informações à pessoa alvo da perícia, 
consequências relacionadas com a inviabilidade da recolha de determinados indícios, após algumas horas ${ }^{32}$, sendo essencial que o examinando ou examinanda compreenda a eventual irreversibilidade da sua decisão.

Caso se mantenha a recusa, deve ser entregue ao examinando ou examinanda um termo de responsabilidade que este ou esta assina, declarando que não pretende a realização da perícia por sua livre vontade, isentando o médico de qualquer responsabilidade pela sua não realização ${ }^{33}$.

\section{b) Possibilidade de um menor de idade recusar a realização de uma perícia médico-legal}

Reportemo-nos agora, especificamente, ao eventual direito do menor de idade em recusar a perícia médico-legal. Considerando o limite etário estipulado pelo legislador no $\mathrm{n}^{\circ} 3$ do artigo $38^{\circ}$ do $\mathrm{CP}$, presume-se que, em princípio, será também

por ser ele que se encontra presente no momento em que a vítima não permite a realização da perícia médico-legal.

32 Referimo-nos aqui, a título de exemplo, a situações em que a vítima é alvo de um crime de natureza sexual e nas quais é fundamental que a análise pericial seja realizada nas primeiras horas após a prática do facto ilícito, numa tentativa de observar, colher, preservar e analisar os vestígios existentes que, numa fase posterior, podem ser úteis na identificação do agressor. Sobre este ponto, veja-se, Teresa MAGALHÃES [et al.] - Da Investigação inicial ao diagnóstico de abuso in Abuso de Crianças e Jovens, da suspeita ao diagnóstico; [s. 1.]: LIDEL, Fevereiro de 2010, pp. 147-187, p. 163.

33 Situação diversa verifica-se quando é o próprio arguido que se recusa a prestar o consentimento informado para a realização da perícia médico-legal. A Lei 45/2004, de 19 de Agosto, que estabelece o regime jurídico das perícias médico-legais e forenses, prevê, no n ${ }^{\circ} 1$ do seu artigo $6^{\circ}$, a obrigatoriedade de sujeição a exame médico-legal, no âmbito de um processo penal (no mesmo sentido, depõe o n ${ }^{\circ} 1$ do artigo $172^{\circ}$ do $\mathrm{CPP}$ ), desde que o mesmo se revele fundamental para o inquérito ou instrução do processo e tenha sido ordenado pela autoridade judiciária competente. Contudo, embora neste caso se justifique a restrição da liberdade do arguido, bem como da sua integridade física e psíquica (defende André Gonçalo Dias PEREIRA, O Consentimento (Informado) ..., ob. cit., p. 25 e 26), o $\mathrm{n}^{\circ} 1$ do artigo $124^{\circ}$ in fine do CDOM, é claro ao referir que o médico perito deve abster-se da realização da perícia sempre que o examinando ou examinanda se recuse a prestar o seu consentimento informado. Assim sendo, ainda que as autoridades policiais possam, no seguimento de uma ordem da autoridade judiciária competente, conduzir coativamente a pessoa ao local designado para a realização da perícia, no caso de o examinando ou examinanda não prestar o seu consentimento, o profissional não deve praticar o ato pericial, sob pena de ser, posteriormente, responsabilizado pela violação da integridade física e psíquica daquele sujeito (todavia, ao não permitir que se cumpra a ordem supramencionada, o examinando ou examinanda pode, eventualmente, ser condenado por um crime de desobediência, nos termos do artigo $348^{\circ}$ do $\mathrm{CP}$ ). Quanto ao facto de o médico perito não cumprir a decisão da autoridade judiciária competente, que obriga à realização do exame médico-legal (isto apenas no caso de a pessoa se recusar), este não deve incorrer num crime de desobediência, pois ao atuar de acordo com as regras deontológicas que regem a sua atividade profissional, o perito age no cumprimento de um dever que lhe é imposto, pelo que se verifica aqui, no nosso entender, uma causa de exclusão da ilicitude nos termos e para efeitos do artigo $31^{\circ}$ do CP. 
a partir dos 16 anos que o jovem terá a possibilidade de recusar ${ }^{34}$ um determinado ato médico, no qual se inclui a perícia médico-legal, fundamentando-se esta recusa numa decisão livre e esclarecida da própria pessoa. Porém, tendo em conta o propósito de uma perícia forense, em determinadas situações, pode ser exigida à criança uma competência e capacidade superiores ao que é necessário para consentir, pois o sujeito alvo da perícia, além de ter de compreender o teor do ato médico que será realizado, tem também de possuir o discernimento para perceber o alcance da sua recusa e a provável irreversibilidade da sua decisão. Assim, no momento em que se verificar uma oposição do jovem à realização do ato pericial, cabe ao profissional presente tentar compreender as razões que justifiquem essa recusa ${ }^{35}$.

No que concerne, especificamente, aos crimes praticados contra a liberdade e autodeterminação sexual do menor de idade, e tendo em conta o tipo de bens jurídicos em causa ${ }^{36}$, não nos parece correto aceitar uma recusa do menor de idade quando esta se baseie, exclusivamente, no receio que este tem em se submeter ao ato pericial, uma vez que existem aqui questões relacionadas com a descoberta da verdade material que também devem ser atendidas; a recusa do jovem deve-se basear numa fundamentação válida e pode exigir um esforço suplementar por parte do médico, no que toca às explicações a fornecer ao examinando ou examinanda. Podem surgir dúvidas quando se trate de situações de perícias urgentes, nas quais não é possível adiar a avaliação pericial, com o intuito de aguardar pela intervenção do tribunal, sem que se verifique o comprometimento dos seus eventuais resultados ${ }^{37}$; parece-nos que neste caso, deve verificar-se, igualmente, um esforço extra do médico no sentido de mostrar ao menor de idade a importância e eventuais benefícios da realização da perícia.

Tal como previamente descrito, e mesmo nos casos em que o objeto da perícia é um menor de idade, parece-nos essencial que o médico saliente as

34 A recusa surge aqui como uma manifestação da autonomia do menor de idade.

35 No caso específico dos crimes de cariz sexual, nos quais alguns dos factos ilícitos são praticados num contexto intra-familiar e em que o agressor é alguém próximo da vítima (a análise é feita por Francisco José Monteiro de Paiva TAVEIRA, Análise do Abuso Sexual em crianças e jovens no contexto intra e extra-familiar, Porto: 2007, trabalho apresentado à Universidade do Porto, no âmbito do Mestrado em Ciências Forenses, como prova de capacidade científica, p. 43), o menor de idade pode recusar a realização da perícia médico-legal receando as consequências que daí possam advir para o agressor, bem como eventuais represálias que ele, jovem, possa sofrer no futuro.

36 Nomeadamente, os bens jurídicos liberdade, autodeterminação sexual e livre desenvolvimento da personalidade do jovem na sua esfera sexual.

37 Referimo-nos aqui, mais uma vez, aos casos nos quais a recolha de vestígios da prática do crime deve ser feita o mais precocemente possível. 
consequências jurídicas da recusa havendo, também aqui, uma necessidade de adequação da linguagem ao sujeito alvo da perícia, perante o caso concreto, tendo em conta a complexidade das questões a abordar. Embora o jovem possa, a partir dos 16 anos de idade ${ }^{38}$, decidir quanto à realização de um determinado ato médico, parece-nos que, no que diz respeito, especificamente, às perícias médico-legais, atendendo ao tipo de bens jurídicos que possam ter sido afetados e à eventual vulnerabilidade do menor de idade perante o caso concreto, a decisão da recusa deve ser conjunta, surgindo aqui o representante legal como uma figura essencial, capaz de auxiliar o jovem na formação da sua vontade ${ }^{39,40}$.

Perante a persistência de recusa do menor de idade na realização da perícia, o médico deverá abster-se de praticar qualquer ato, facultando ao jovem o devido termo de responsabilidade que, após ser assinado, deverá ser anexado ao processo, justificando a não realização da perícia ${ }^{41,42}$. Posteriormente, o médico deverá remeter para o tribunal o relatório pericial, no qual é referido que o menor de idade não prestou o seu consentimento para que a perícia fosse realizada.

Embora a lei penal estabeleça os 16 anos como idade-referência, entendemos que, tanto o tribunal como o médico, devem atender à recusa de um jovem com idade inferior a 16 anos, desde que este possua o discernimento exigido por lei e que a sua decisão seja fundamentada. Porém, uma outra questão surge neste ponto: deverá o tribunal ordenar a realização da perícia médico-legal, mesmo contra a vontade da criança, sendo que esta decisão é suscetível de colocar em causa a autonomia e autodeterminação deste? Estando perante factos ilícitos que violem, porventura, a liberdade, autodeterminação sexual bem como o livre desenvolvimento da personalidade do

38 Importa salientar, mais uma vez, que além do fator idade, o CP exige ainda que o jovem possua o discernimento adequado para compreender o sentido e alcance da sua decisão, não sendo a idade o único elemento atendível para que a decisão seja válida à luz do ordenamento jurídico português.

39 Porém, acreditamos que a última decisão deve pertencer sempre ao menor de idade.

40 De ressalvar que, nos casos em que o jovem se manifeste contra a presença do representante legal no local onde a perícia será realizada, a sua vontade deve ser atendida, de modo a que o examinado ou examinada se sinta confortável durante a realização da mesma.

41 A recusa deve ser documentada no respetivo processo, de forma cuidadosa, uma vez que dela resulta a não realização de um determinado ato que se presume no melhor interesse do menor de idade. Sobre esta questão, veja-se o Documento-Guia sobre o Consentimento Informado - texto que integra os principais assuntos debatidos no "Seminário sobre o consentimento informado e o papel das comissões de ética para o seu correto uso" - ARS Norte, Administração Regional de Saúde do Norte, I.P < http://portal.arsnorte.min-saude. pt/portal/page/portal/ARSNorte/Comiss\%C3\%A3o\%20de\%20\%C3\%89tica/Ficheiros/Consentimento_Informado_Doc_Guia.pdf >.

42 Nos casos em que o menor de idade possui os requisitos legalmente exigidos para recusar o ato médico, o termo de responsabilidade deve ser assinado pelo próprio. 
menor de idade na sua esfera sexual, poderá também ser necessário atender a interesses específicos da própria sociedade que, através do Ministério Público, procura o bem-estar e a proteção da criança. Ainda que o superior interesse da criança passe também pela descoberta da verdade material, o que por vezes só é possível através da realização de uma perícia médico-legal e conclusões da avaliação pericial, não nos parece correto que o ato médico seja realizado com recurso à força, numa clara violação dos direitos, liberdades e garantias constitucionalmente protegidos ${ }^{43,44,45}$. Assim, cabe ao juiz, perante o caso concreto, proceder a uma ponderação quanto à necessidade de realização da perícia e a sua essencialidade para a descoberta da verdade material, nunca esquecendo que, enquanto sujeito de direitos, o jovem tem também um direito à reserva da intimidade da vida privada ${ }^{46}$.

Tratando-se de situações em que o jovem não cumpre os requisitos necessários para prestar um consentimento válido perante a lei e o facto ilícito é praticado pelo seu representante legal, o médico pode ser confrontado com novas dificuldades, face à recusa para a realização da perícia médico-legal, por parte de quem detém o exercício das responsabilidades parentais. Perante esta realidade, deve o profissional solicitar a intervenção das autoridades judiciárias competentes, com vista à limitação, ainda que temporária, do exercício das responsabilidades parentais ${ }^{47}$; deste modo, após decisão judicial que ordene o suprimento das responsabilidades parentais, o médico tem o

43 Mesmo não tendo ainda atingido a maioridade civil, o menor de idade continua a ser um sujeito de direitos com personalidade jurídica que, tal como qualquer cidadão, carece de proteção do Estado, face à violação dos seus direitos.

44 Pode surgir aqui a necessidade de explicar novamente o procedimento pericial a realizar, as técnicas utilizadas, bem como os benefícios da sua realização, numa tentativa de dissipar todas as dúvidas e receios da criança.

45 De salientar que, embora o médico tenha em conta a vulnerabilidade do jovem no decorrer de uma perícia médico-legal e faça tudo ao seu alcance para que o examinado ou examinada se sinta o menos desconfortável possível (principalmente quando nos referimos às situações em que está em causa a prática de um crime contra a liberdade e autodeterminação sexual da vítima) o ato pericial pode, eventualmente, consubstanciar um segundo evento traumático para o menor de idade.

46 Entre nós previsto no $\mathrm{n}^{\circ} 1$ do artigo $26^{\circ}$ da CRP, na linha do artigo $12^{\circ}$ da Declaração Universal dos Direitos do Homem e do artigo $8^{\circ}$ da Convenção Europeia dos Direitos do Homem

47 Atendendo ao previsto no $\mathrm{n}^{\circ} 1$ do artigo $69^{\circ}$ da CRP, quando se verifique o exercício abusivo das responsabilidades parentais por parte do detentor deste poder-dever, a criança tem direito à proteção da sociedade e do Estado, com vista ao seu desenvolvimento. No mesmo sentido, o n ${ }^{\circ} 6$ do artigo $46^{\circ}$ do CDOM salienta a possibilidade de o médico requerer judicialmente o suprimento do exercício das responsabilidades parentais, com o objetivo de salvaguardar os interesses de pessoa incapaz de prestar consentimento, quando estejamos face a situações em que o representante legal decide contrariamente aos direitos e interesses do examinando ou examinanda. 
dever de realizar os procedimentos que se revelem necessários e adequados à recolha de quaisquer indícios que possam existir, salvaguardando-se assim o superior interesse da criança, bem como os interesses da própria sociedade. Porém, tendo em conta que, em algumas situações, a urgência na recolha de determinados indícios é um fator crucial para que se possa concluir pela prática de um ilícito criminal, encaramos como legítima a atuação do médico que realiza a perícia médico-legal sem prévia autorização judicial; todavia, acreditamos que esta atuação por parte do médico, apenas se deve verificar quando o adiamento causado pela tentativa de intervenção do tribunal, seja suscetível de colocar em risco a viabilidade da recolha de determinados indícios ${ }^{48}$, assim como o bem-estar do menor.

\section{c) Cuidados especiais durante o exame a um menor de idade}

Ainda no que diz respeito a perícias médico-legais envolvendo menores de idade, o médico deve sempre ter em conta o natural pudor da criança, interrompendo a prática de qualquer ato, quando esta assim o solicitar ${ }^{49}$, de modo a respeitar a sua dignidade ${ }^{50}$; do que resulta dito, é possível concluir que o profissional deve atuar de modo a salvaguardar, sempre que possível, o superior interesse da criança.

\section{CONSIDERAÇÕES FINAIS}

A utilização indistinta de conceitos como criança, menor de idade, jovem, adolescente, entre outros, com o objetivo de caraterizar uma só realidade, pode levantar sérias dúvidas aos profissionais que, diariamente, recebem nos serviços de clínica médico-legal, indivíduos com idade inferior a 18 anos, vítimas dos mais variados tipos de crime e cuja avaliação pericial se revela essencial; a própria divergência legal entre o direito penal e o direito civil, no que toca à idade para consentir e idade na qual se atinge a maioridade civil, pode fazer com que o perito médico se confronte com sérias dificuldades no

48 Referimo-nos aqui a situações em que é praticado um crime contra a liberdade e autodeterminação sexual do jovem, do qual resultem, por exemplo, vestígios biológicos (sémen, saliva, entre outros) que devem ser recolhidos até $72 \mathrm{~h}$ após a prática do facto ilícito, como as analisadas por Karen Elódia Brito SILVA, Abuso Sexual de Crianças: aspectos jurídicos a ponderar no âmbito da perícia médico-legal, Coimbra: 2010, dissertação apresentada à Faculdade de Medicina da Universidade de Coimbra, no âmbito do Mestrado em Medicina Legal e Ciências Forenses, pp. 29 e 30.

49 Neste sentido, veja-se Teresa MAGALHÃES A Intervenção médico-legal em casos..., ob. cit., p. 182.

50 Esta exigência decorre do $\mathrm{n}^{\circ} 3$ do artigo $172^{\circ}$ do CPP. 
decorrer da sua atividade. Todavia, a lei penal é clara ao não permitir que o consentimento informado seja prestado, por exemplo, por um jovem de 15 anos, mesmo que este possua o discernimento necessário; deste modo, quando se trate de uma vítima com idade inferior a 16 anos ou que não possua a capacidade exigida por lei, o consentimento informado deve ser prestado pelo seu representante legal. Porém, acreditamos que o menor de idade deve ser sempre envolvido em todo o processo de esclarecimento e decisão e a sua opinião deve ser valorada ${ }^{51}$, numa clara atitude de respeito pela sua vontade, autonomia, autodeterminação e livre desenvolvimento.

Resumo: 0 consentimento informado de menores de idade na atividade pericial forense

0 consentimento informado apresenta-se, hoje em dia, como um elemento fulcral na relação que se estabelece entre médico e paciente. Porém, as dúvidas em torno da questão do consentimento, podem adquirir maior dimensão quando o ato médico em causa envolve um menor de idade. No estudo que aqui se apresenta, abordaremos alguns aspetos fundamentais do consentimento informado, incluindo a obrigatoriedade do dever de esclarecimento prévio, analisando esta temática no âmbito da atividade pericial forense; analisaremos ainda algumas dificuldades com as quais o médico, frequentemente, se depara no decorrer de uma perícia médico-legal, quando a vítima de um ilícito criminal é um menor.

Palavras-Chave: Consentimento informado; menor de idade; perícias médico-legais; dever de esclarecimento; discernimento e capacidade para consentir.

Summary: Minors informed consent in forensic activity

Informed consent presents itself today as a key element in the relationship established between physician and patient. However, doubts over the issue of informed consent, can increase when the medical procedure in question involves a minor. In our study, we discuss some key aspects of informed consent, including a requirement of prior clarification, analyzing this issue in the context of forensic activity; we will also analyze some difficulties that physicians often encounters during the process of a forensic medicine examination, when the victim of a criminal offense is a minor.

Key-Words: Informed consent; minor; forensic medicine examinations; duty of clarifying; insight and ability to consent.

Pedido de separatas:

ANA AMORIM

anasamorim@hotmail.com

51 De acordo com as regras deontológicas que regem a atividade médica, a opinião de um menor de idade deve ser sempre tomada em consideração, tendo em conta a maturidade do jovem em concreto. Ver $\mathrm{n}^{\circ} 3$ do artigo $46^{\circ}$ do CDOM. 